Es geht aus dem Vorstehenden hervor, dass die Einwirkung des Barytwassers auf das Nitril der Isoäpfelsäure in ganz anderer Weise verläuft als die der konzentrierten Salzsäure. Die Verseifung dieses Nitrils mit Barytwasser geht viel langsamer vor sich als mit konzentrierter Salzsäure. Es ist nicht unwahrscheinlich, dass durch das anhaltende Kochen mit Barytwasser das Nitril resp. die daraus vielleicht zunächst gebildete Oxäthylidensuccinaminsäure oder $\alpha$-Isoäpfelsäure tiefergreifend zersetzt wird, wobei sich vielleicht ein ähnlicher Prozess vollzieht, wie er beim Kochen von Chlorcitramalsäure mit Barytwasser vor sich geht. Es ist jedoch auch die Möglichkeit nicht ausgeschlossen, dass vielleicht eine Kondensation eintritt, wie sie beim Kochen von Brenztraubensäure allein mit Barytwasser unter Bildung von Uvinsäure resp. Uvitinsäure beobachtet ist. Ich werde versuchen, sobald ich in den Besitz einer grösseren Menge der Säure gelangt bin, wie sie beim Kochen des Einwirkungsproduktes der Brenztraubensäure auf Cyankalium sich bildet, über die Entstehung derselben, bezw. ihre Zusammensetzung und Eigenschaften weitere Aufschlüsse zu erhalten und dann in einer weiteren Mitteilung darïber berichten.

Mitteilungen aus dem pharmazeutisch-chemischen Laboratorium der technischen Hochschule in Braunschweig.

Von H. Beckurts.

\title{
I. Zum Nachweis von Salicylsäure und Benzoesäure in der Milch.
}

\author{
Nach Untersuchungen von G. Breustedt.
}

(Fingegangen den 1. III. 1899.)

In den Vereinbarungen zur einheitlichen Untersuchung und Beurteilung von Nahrungs- und Genussmitteln, sowie Gebrauchsgegenständen für das Deutsche Reich ${ }^{1}$ ) wird der Nachweis von Salicylsäure in der Milch nach der Methode von Ch. Girard ${ }^{\mathbf{2}}$ ), derjenige von Benzoesäure aber nach E. Meissl ${ }^{8}$ ) geführt. Die letztere Methode ist unständlich und um so überflüssiger, da die

1) Lntwurf, festgestellt nach den Beschlüssen der auf Anregung des Kaiserl. Gesundheitsamtes einberufenen Kommission deutscher Nahrungsmittelchemiker. Heft I. J. Springer, Berlin 1897.

2) Zeitschr. anal. Chem. 1883, 22, 277.

3) Ebenda 188:, 21, 531 . 
Benzoesäure auch nach dem Verfahren von Girard, ev. neben Salicylsäure, in den Aether übergeht und in dem Verdunstungsrückstand desselben nachgewiesen werden kann. Aber auch das Verfahren von Girard leidet vielfach an einem Uebelstande, nämlich daran, dass Emulsionsbildung auftritt, deren Beseitigung mit Schwierigkeiten verknüpft ist. Wahrend nun Girard die Milch durch Zusatz von Essigsäure und einer Lösung von salpetersaurem Quecksilberoxyd unbekannter Konzentration koagulieren lässt, ist es nach unseren Versuchen vorteilhafter, die Abscheidung des Kaseins nach Ritthausen mittelst Kupfersulfat auszuführen und hierzu folgendermafsen zu verfahren:

$25 \mathrm{ccm}$ Milch werden mit $25 \mathrm{ccm}$ Wasser und $10 \mathrm{ccm}$ Fehlingscher Kupfersulfatlösung versetzt, worauf man ca. $2,5 \mathrm{ccm}$ Norm.Kalilauge so vorsichtig hinzufügt, dass die Flüssigkeit noch deutlich sauer reagiert. Man erwärmt kurze Zeit im Wasserbade und saugt das ausgeschiedene Kupferkaseïnat, welches überdies alles Fett einschliesst, ab. Das völlig klare, meist noch etwas kupferhaltige Serum wird mit einigen Tropfen verdünnter Salzsäure versetzt und nun einmal mit Aether ausgeschüttelt. Nachdem die sehr prompt eintretende Abscheidung des Aethers erfolgt ist, trennt man denselben, lässt verdunsten und weist im Verdunstungsrückstande Salicylsäure und Benzoesäure nach.

1. Es ist nur Salicylsäure vorhanden.

Zusatz von verdünnter Eisenchloridlösung (1,005-1,01 spez. Gew.) bewirkt violette Färbung.

2. Es ist nur Benzoesäure vorhanden.

a) Dieselbe wird erkaunt dadurch, dass man den Verdunstungsrückstand in 1 bis $2 \mathrm{ccm}$ Wasser löst, einen Tropfen einer $10 \%$ igen Eisenchloridlösung hinzufügt und event. einige Minuten kocht; bei Gegenwart von Benzoesäure tritt Abscheidung brauner Flocken von benzoesaurem Eisen auf; oder dadurch, dass man

b) den Aetherrückstand mit zwei Tropfen 50\%iger Ameisensäure mischt, mit Kalkmilch übersättigt, eintrocknet, und den Rückstand in einseitig geschlossenem Glasrohr vorsichtig erhitzt. Bei Gegenwart von Benzoesäure macht sich ein deutlicher Geruch nach Bittermandelöl bemerkbar, auch wenn gleichzeitig Salicylsäure zugegen sein sollte, so dass auf diese Weise Benzoesäure neben Salicylsäure recht gut erkannt werden kann.

Noch einfacher gestaltet sich der Nachweis der Salicylsäure in folgender Weise: In einem mit angeschmolzener Kugel von etwa 
$20 \mathrm{ccm}$ Inhalt versehenen grossen Reagensglase werden $10 \mathrm{ccm}$ Milch mit $10 \mathrm{ccm}$ rauchender Salzsäure bis zur Rotfärbung erhitzt. Nach dem Abkühlen mischt man mit $20 \mathrm{ccm}$ Aether, hebt den sich schnell absetzenden Aether ab, lässt diesen verdunsten, schüttelt das zurückbleibende Fett kräftig mit etwa $5 \mathrm{ccm}$ heissem Wasser, filtriert sofort und versetzt das Filtrat mit einigen Tropfen einer $1 \%$ igen Eisenchloridlösung. Es gelang auf diese Weise noch 0,0005 g Salicylsäure in $10 \mathrm{ccm}$ Milch nachzuweisen.

Ueberall dort, wo die Bestimmung des Fettgehaltes einer Milch nach der Methode von Schmid-Bondzinsky ausgeführt wird, lässt sich der Nachweis von Salicylsäure in dem zur Wägung gelangten Fette nach vorstehenden Angaben ausführen.

\title{
II. Die massanalytische Bestimmung der Alkaloide.
}

\author{
Von O. Linde.
}

(Eingegangen den 1. III. 1899).

Seit in den letzten Dezennien die Bereitung der pharmazentischen Präparate, zuerst der chemischen, dann auch der galenischen, aus den Apothekenlaboratorien in die chemischen Fabriken übergegangen, ist man bestrebt gewesen, Prüfungsmethoden aufzustellen, um sich von der normalen Beschaffenheit dieser Präparate überzeugen zu können. Verhältnismässig leicht war dies bei den Chemikalien, schwieriger gestaltete sich die Sache bei den Extrakten, Tinkturen u. dergl. Was diese anbelangt, so musste man vor allen Dingen die wirksamen Bestandteile derselben, bezw. die der Drogen, aus denen die betr. Präparate hergestellt werden, genau kennen, was vielfach bis jetzt noch nicht in genügendem Malse der Fall ist. Eine Ausnahme machen diejenigen Drogen und Arzneibereitungen, deren Wirksamkeit auf ihren Gehalt an Alkaloiden oder alkaloidähnlichen Stoffen zurückzuführen ist; mit der Wertbestimmung dieser hat man sich deshalb in letzter Zeit besonders ausgiebig beschäftigt.

Wenn nun auch nicht anzunehmen war, dass die hier in Betracht kommenden Drogen und Präparate nur ein em der in ihnen enthaltenen Körper ihre Heilkraft verdanken, etwa das Opium dem Morphin, die Chinarinde dem Chinin, sondern dass auch noch andere Stoffe daran teil haben, so sind doch diese letzteren zu dem besonders stark wirkenden Körper häufig in einem annähernd gleichen Verhältnis zugegen, so dass der Wirkungswert der Droge bezw. der daraus gefertigten Arzneimittel nach diesem hauptsächlichsten Bestandteil beurteilt werden kann. 